NBER WORKING PAPER SERIES

NEGOTIATOR BEHAVIOR

UNDER ARBITRATION

David E. Bloom

Christopher L. Cavanagh

Working Paper No. 2211

NATIONAL BUREAU OF ECONOMIC RESEARCH

1050 Massachusetts Avenue

Cambridge, MA 02138

Apri1 1987

NSF Grant SES-8309148 provided partial support for this research. The authors are indebted to Robert Gibbons for helpful discussion. This paper is forthcoming in American Economic Review Papers and Proceedings, May 1987. The research reported here is part of the NBER's research program in Labor Studies. Any opinions expressed are those of the authors and not those of the National Bureau of Economic Research. 
NBER Working Paper \#2211

April 1987

Negotiator Behavior Under Arbitration

$\underline{\text { ABSTRACT }}$

The emerging empirical literature on the economics of arbitration has focused primarily on the behavior of arbitrators under alternative forms of arbitration. This article suggests that it is natural for empirical economists to now expand their focus to include issues related to the behavior of negotiators. In this connection, three key aspects of negotiator behavior are discussed: (1) the decision to settle a dispute voluntarily or to proceed to arbitration; (2) the strategy for selecting an arbitrator; and (3) the final bargaining position to advance before an arbitrator .

David E. B Toom Department of Economics Harvard University Cambridge, MA 02138
Christopher L. Cavanagh Department of Economics Harvard University Cambridge, MA 02138 


\section{Negotiator Behavior Under Arbitration}

David E. Bloom and Christopher L. Cavanagh

Bilateral bargaining lies at the heart of many important economic institutions. Even when there are substantial gains to trade, disputes are a natural and persistent element of bargaining situations. In order to economize on the cost of disputes, a number of mechanisms for preventing or resolving disputes have evolved. The public court system is perhaps the best-known of these mechanisms, although private adjudication systems also exist. Moreover, because of increasing costs and congestion in the public court system, private mechanisms for adjudicating disputes have, in recent years, abounded in both number and scope.

One of the most popular private mechanisms for adjudicating disputes is arbitration. For example, in the area of labor-management relations, there were over 100,000 arbitration cases in the U.S. in 1985 - about four times the number that took place just fifteen years earlier. Indeed, over the past two decades, nearly half the states in the U.S. have established interest arbitration mechanisms to resolve pay disputes involving groups of public employees. Arbitration is also widely used to resolve commercial disputes and, more recently, to resolve selected categories of civil disputes that might otherwise congest the public court system.

Although arbitration mechanisms can vary substantially in design, they all tend to involve a third-party to a dispute determining its resolution. Arbitration guarantees finality in the resolution of a dispute, generally in a timely and legitimate fashion that limits the erosion of a bargaining relationship that might result from the existence of a dispute. 
Arbitration is a fascinating mechanism for economists to study. First, the possibilities for empirical analysis are often quite extraordinary. For example, in comparison to the public court system, there is more heterogeneity in the types of "arbitration experiments" available and less heterogeneity in the data (i.e., similar disputes are dealt with according to a wide variety of arbitration mechanisms). Moreover, the outcomes of wage and salary arbitration are relatively easy to quantify for purposes of empirical analysis and permit econometric models to build on much existing research on wage determination. Thus, the study of arbitration -- a relatively simple mechanism for resolving disputes -- may yield important insights into more complex legal mechanisms that are relatively difficult to model and to subject to empirical analysis.

Second, arbitration systems provide excellent settings for testing some of the most basic propositions of game theory. Arbitration is essentially a game with simple and well-specified rules in which a small number of players can be easily identified. The availability of "real-world" data on situations in which there are incentives to behave strategically provides remarkable opportunities for the analysis of game-theoretic behavior.

Third, insofar as arbitration mechanisms can be structured in different ways, studying arbitration might lead to improved designs. Indeed, theoretical work on arbitration has raised a number of policy-relevant issues whose resolution ultimately depends upon the results of empirical analysis.

The emerging empirical literature on the economics of arbitration has been primarily concerned with modeling the behavior of arbitrators under 
alternative forms of arbitration. It seems natural that the empirical literature turn next to consideration of the behavior of negotiators under arbitration (which typically depends critically on expectations about arbitrator behavior). Our chief purpose in the remainder of this article is to identify some of the issues that might sensibly be raised by empirical economists studying arbitration from the point of view of the negotiating parties.

In a typical bargaining/arbitration situation, there are three key problems that negotiators must solve. First, they must decide whether to settle their dispute voluntarily or to proceed to arbitration. Second, they must adopt a strategy for selecting an arbitrator. Third, they must bargain prior to arbitration and, if they are unable to settle voluntarily, they must formulate final positions to advance in arbitration. The remainder of this article will discuss each of these three choice variables in turn. ${ }^{1}$

\section{Negotiation vs. Arbitration}

The American system of industrial relations exhibits a strong normative preference for resolving disputes without the aid of third parties. Thus, Stevens' (1966) observation that arbitration mechanisms can be designed in ways that discourage their use was greeted enthusiastically by the proponents of arbitration. Briefly, Stevens likened arbitration to the strike as a mechanism for imposing costs of disagreement on bargainers and thereby promoting voluntary settlements. These costs are composed of the direct costs of using an arbitration mechanism and the indirect costs that are generated by 
the interplay of arbitral uncertainty and disputants' risk aversion.

Subsequent work by Farber and Katz (1979) formalized Stevens' notion by deriving expressions for a contract zone, i.e., a locus of potential settlement points, all of which are preferred by both parties to the settlement expected under arbitration. A contract zone may be generated either by the costs of arbitration or by at least one bargainer having overly pessimistic expectations about an arbitrator's award. Conversely, a contract zone will tend to be small or nonexistent when at least one bargainer has overly optimistic expectations about an arbitrator's award.

These early analyses assumed that voluntary settlements would be reached whenever there was a contract zone. Thus, divergent and mutually inconsistent expectations seemed to be a key determinant of the resort to arbitration. More recent work has pointed out that the existence of a contract zone is necessary, but not sufficient, for arbitration to lead to a voluntary settlement because there may be substantial direct costs of negotiation as well as uncertainty about settlement points within the contract $z$ one; it follows that wider contract zones do not, ceteris paribus, imply lower impasse probabilities (Bloom, 1981).

One of the most striking facts about arbitration requiring explanation is the substantial fraction of bargaining cases that end up being arbitrated: the steady-state rate of arbitration usage seems to vary between 15 and 30 percent in states with compulsory interest arbitration laws. In view of this fact, the theory that divergent expectations about arbitrator behavior explain the use of arbitration is less than satisfactory. It seems unlikely that 
bargainers would consistently be overly optimistic about the size of an arbitration award in the context of what is essentially a repeated game. Even in the context of one-shot bargaining, rational bargainers will tend to reconcile their prior expectations about an arbitrator's behavior in the negotiations leading up to arbitration (e.g., see Geanakopolos and Polemarchakis, 1982). Thus, alternative explanations are worth exploring.

Arbitration usage rates are not notably different in states with conventional arbitration provisions and those with final-offer arbitration provisions. $^{2}$ This fact tends to contradict two early, but still influential, views about arbitration: (1) the view that final-offer arbitration would induce risk-averse bargainers to make concessions until their bargaining positions eventually overlapped, thereby eliminating the need for arbitration, and (2) the view that split-the-difference behavior on the part of conventional arbitrators (whether actual or perceived) would tend to "chill" negotiators from making concessions in the bargaining that precedes arbitration and thereby increase the probability of a dispute ending up in arbitration.

Another early theory held that arbitration would have a "narcotic effect" on bargainers, according to which bargainers would habitually avoid the arduous demands of bargaining in favor of arbitrated outcomes. Simple descriptive statistics do seem to indicate that there is substantial variation in arbitration usage across bargaining units. Whether this tendency is indeed evidence of a genuine narcotic effect is difficult to test because it requires establishing serial correlation in the use of arbitration -- after controlling for heterogeneity across bargaining units. 
Future analyses of the resort to arbitration might usefully build upon the notion that bargaining parties are not internally homogeneous entities with identical preferences. Bargainers often have constituencies whose future political support they desire. Insofar as arbitrators can be viewed as paid "scapegoats," the parties' final positions and their resort to arbitration might be modeled in a principal-agent framework. In this spirit, Crawford (1982b) develops a formal game-theoretic model of bargaining impasses based on the notion that parties may rationally commit to irreconciliable bargaining positions. The political pressure of the constituency makes concession after commitment costly and so can lead to impasse.

To date, there have been few attempts to empirically implement a structural model of the arbitrate/negotiate decision. Although some studies have been conducted using experimental data, further analysis, especially using available data from actual arbitration systems, is much needed.

\section{The Selection of Arbitrators}

One of the most salient differences between arbitration and the public court system is that disputants typically have some say in the appointment of arbitrators. The two leading arbitrator selection mechanisms operate by having an impartial agency (such as the American Arbitration Association) supply disputants with identical lists of an odd number of arbitrators (along with information on their backgrounds, fees, etc.). Alternate strike mechanisms work by having each party alternately cross a name off the 1 ist with the last name remaining becoming the appointed arbitrator. Rank-veto 
mechanisms work by having the parties each veto a prespecified number of arbitrators, rank the remaining ones in order of their preference, and then refer the list back to the agency which then makes an appointment in accordance with those preferences. The opportunity for disputants to express their preferences for different arbitrators suggests an element of strategic interaction according to which negotiators may veto or give relatively unpreferred rankings to highly preferred arbitrators in an attempt to manipulate the selection process.

The analysis of arbitrator selection is interesting for several reasons. First, it yields direct information on the characteristics of arbitrators that negotiators find desirable. Second, measuring the similarity of union and employer preferences for individual arbitrators may yield insights into whether collective bargaining and arbitration are primarily institutions of conflict or cooperation. Third, it can provide information on the strategic sophistication of negotiators and on the importance of strategic interaction in bargaining. Finally, as we argue below, the process of arbitrator selection may be closely related to the use of arbitration.

The empirical literature on the selection of arbitrators is still in its infancy and much important work remains to be done. In a recent paper (1986b), we analyzed a set of data on actual union and employer rankings of different panels of arbitrators under a rank/veto mechanism. The results indicate that unions and employers have similar preferences: in favor of lawyers, more experienced arbitrators, and arbitrators who seem to have favored their side in the past. In addition, both sides exhibit strong preferences about having economists serve as arbitrators, with employers being 
in favor and unions being against. The analysis also tests whether the observed rankings data reveal the negotiators' true preferences over arbitrators. The results provide no support for the hypothesis of strategic misrepresentation of preferences by either side. Nonetheless, further empirical analysis of arbitrator selection is desirable, especially in the context of alternate strike mechanisms in which empirically falsifiable hypotheses about strategic behavior can be tested directly.

In another paper (1986a), we researched two aspects of the arbitrator selection phase of an arbitration system: (1) the strategies and outcomes of the selection "sub-game" and (2) the impact of selection mechanisms on the bargaining environment. Our results on the selection sub-game indicate that there is frequently no incentive to strategically misrepresent preferences -depending on the bargainers' preferences over arbitrators and on how much information they have about the other side's preferences. Thus, our earlier empirical results do not necessarily imply that negotiators are unsophisticated or irrational in their behavior. On the other hand, individually rational behavior in situations in which negotiators do have incentives to strategically misrepresent their preferences can result in inefficient selections.

This work also led us to conclude that arbitration is not necessarily best viewed in a purely static framework in which the size of the contract zone is fixed by an unchanging amount of arbitral uncertainty. We developed a model of the bargaining/arbitration process that has three distinct stages: (1) bargaining that takes place before the panel of prospective arbitrators is announced; (2) bargaining that takes place after the panel of prospective 
arbitrators is announced but before a particular arbitrator is selected; and (3) bargaining that takes place after a particular arbitrator is selected. Corresponding to each separate stage is a specific degree of uncertainty about the final resolution of the dispute. Furthermore, the degree of uncertainty tends to decrease as the parties move from one stage to the next. Although empirical analysis of the relationship between arbitrator selection mechanisms and the probability of impasse have yet to be conducted, we suspect that a dynamic mechanism that confronts bargainers with a varied set of bargaining environments is likely to provide them with better opportunities to reach agreement than a static mechanism that presents them with a single alternative. In practice, there is a substantial amount of voluntary settlement in each of the distinct stages of the bargaining/arbitration process.

\section{Determination of Negotiators' Arbitration Positions}

The earliest models of negotiators' arbitration positions presuppose that arbitrator preferences are imperfectly known to the disputants and depend solely on the exogenous facts of a dispute. In such a model, the mean of the distribution of arbitrator preferences becomes the focal point around which negotiators bargain, both in the negotiations that precede arbitration as well as in the arbitration process itself. If that focal point is different from the average settlement that would be negotiated in the absence of arbitration, the "option to arbitrate" will bias negotiated settlements. In addition, the negotiated settlements may not be Pareto efficient if there are multiple issues in dispute (see Crawford, 1979, 1982a). 
Final-offer arbitration provides negotiators with an incentive to moderate their positions since less extreme positions presumably have higher probabilities of being selected by an arbitrator. However, because smaller payoffs are associated with more moderate positions, negotiators also have some incentive to adopt extreme positions. In the context of single-issue disputes, Nash final offers have the following properties: (1) the final offer of the more risk-averse negotiator will lie closer to the mean of the prior distribution of arbitrator preferences than the final offer of the less risk-averse negotiator; (2) increasing arbitral uncertainty by lowering the density of arbitrator preferences at the mean of the Nash pair of final offers causes those offers to diverge; and (3) even if both negotiators are risk neutral, arbitral uncertainty will cause their final offers to diverge (symmetrically) from the median of the arbitrator's preference distribution (see Farber 1981). ${ }^{3}$

Under conventional arbitration, negotiators have literally no incentive to express a final position if arbitrator preferences are conditioned solely on exogenous background information. The fact that they almost always do suggests that the true model of arbitrator preferences may be somewhat different. An alternative (but equally polar) model of the behavior of conventional arbitrators is one in which they simply "split-the-difference" between the parties' final positions. The fact that conventional arbitration decisions typically lie near the average of the parties' final positions provides at least some empirical support for this view, although proper evaluation of this piece of data requires a model of negotiator behavior.

It seems obvious that the negotiators optimal final offers will diverge 
if arbitrators mechanically "split-the-difference." An intermediate model, in which an arbitrator's preferred settlement depends on both the exogenous facts and the parties' final positions, would seem to be more plausible. This formulation suggests that arbitrators extract a useful signal about negotiator preferences from their final positions. If so, it follows that negotiators will have an incentive to communicate strategically to the arbitrator through their final offers.

The notion that negotiator final offers are attempts to "position the arbitrator," suggests that arbitrator and negotiator behavior should be modeled as a three-party game. It also suggests that econometric attempts to estimate the parameters of arbitrator preference functions by studying how arbitrator's behave when confronted with different sets of facts and final positions may be misspecified insofar as the final positions are endogenously determined. Put another way, it remains an open empirical question whether arbitrators should mainly be viewed as individuals who (1) impose on the negotiators their exogenous preferences or (2) seek to learn about the disputants' preferences from the relationship between the facts and final positions in an attempt to search for outcomes that maximize the disputants' welfare. Gibbons (1986) has begun the important task of modeling arbitrator behavior in the context of a three-party game of arbitration, although further work remains to be done.

In this connection, it is worth reflecting on the relation between the bargaining process that precedes arbitration and the arbitration game itself. Indeed, it is only reasonable to suppose that split-the-difference behavior on the part of arbitrators will "chill" negotiators from making concessions in 
the bargaining that precedes arbitration if one imagines that (1) negotiating concessions cannot be "taken back" in arbitration and (2) arbitrators extract information from the parties' pre-arbitration behavior. In practice, both conditions are likely to be satisfied, suggesting a close coupling of behavior in negotiations and arbitration. Perhaps a small change in the design of arbitration mechanisms, in which arbitration hearings would be conducted without reference to the negotiations that preceded arbitration (i.e., de novo), would uncouple the two games and better serve the interests of both the negotiators and public policy.

Simple facts about the relation between negotiators' final positions under conventional and final-offer arbitration could be a good starting point for further theoretical work. Table I reports the average of employer and union final offers (EFO and UFO) in the two types of salary arbitration cases that took place in New Jersey in the years 1981-1984. As the table makes clear, the parties' positions in conventional arbitration (CONV) tend to lie outside the bounds of their positions in final-offer arbitration (FOA). This pattern is consistent with the predictions of the very simplest arbitration models according to which final-offer arbitration induces concessionary behavior by risk-averse bargainers while conventional arbitration chills the negotiation process that precedes arbitration. It remains to be seen whether more complete models of negotiator behavior under arbitration can further enrich our interpretation of these facts. 


\section{Table I}

Union and Employer Final Salary Offers (expressed as percent increases)

$\begin{array}{llll}1981 & 1982 & 1983 & 1984\end{array}$

\begin{tabular}{lllll} 
& \multicolumn{5}{c}{ CONV } \\
EFO & 6.4 & 5.1 & 6.3 & 6.2 \\
UFO & 9.6 & 9.2 & 9.0 & 8.3
\end{tabular}

FOA

$\begin{array}{lllll}\text { EFO } & 7.2 & 7.2 & 6.5 & 6.6 \\ \text { UFO } & 9.0 & 9.3 & 8.3 & 7.8\end{array}$

Source: Authors' calculations based on New Jersey arbitration awards. 
Notes

${ }^{1}$ Provided arbitration is not compelled by law, the parties must jointly (and privately) decide whether they will use arbitration to resolve their disputes. The decision to arbitrate can be made either before or at the time a particular dispute arises. Although ex ante agreements to arbitrate disputes raise interesting economic issues, they are beyond the scope of this article.

2 Under conventional arbitration, the arbitrator simply renders a decision that consists of his or her best judgement of a fair settlement. In contrast, the arbitrator is constrained to render a decision that consists of one or the other of the parties' final offers, without compromise, under final-offer arbitration.

3

Although the negotiators' final offers are interdependent in this simple model, they may be independent of each other in a system of tri-offer arbitration such as the one that operates in Iowa. Ashenfelter, Dow, and Gallagher (1986) have done an interesting empirical analysis of the Iowa system that attempts to test a simple model of optimal negotiator behavior. 
Ashenfelter, Orley, James Dow, and Daniel Gallagher, "Arbitrator and Negotiation Behavior Under an Appelate System," Unpublished mimeo,August 1986.

Bloom, David E, "Is Arbitration Really Compatible with Bargaining?" Industrial Relations, Fal1 1981, 20, 233-244.

and Christopher L. Cavanagh, "An Analysis of the Selection of Arbitrators," American Economic Review, June 1986, 76, 408-422.

, "An Analysis of Alternative

Mechanisms for Selecting Arbitrators," Harvard Institute of Economic Research Discussion Paper No. 1224, April 1986.

Vincent P. Crawford, "On Compulsory Arbitration Schemes," Journal of Political Economy, February 1979, $87,131-160$.

, "Compulsory Arbitration, Arbitral Risk and Negotiated Settlements: A Case Study in Bargaining Under Imperfect Information," Review of Economic Studies, January 1982a, 49, 69-82. May $1982,50,607-637$.

Farber, Henry S., "An Analysis of Final-0ffer Arbitration," Journal of Conflict Resolution, December 1980, 35 , 683-705.

and Harry C. Katz, "Interest Arbitration, Outcomes, and the Incentive to Bargain," Industrial and Labor Relations Review, October $1979,33,55-63$.

Geanakoplos, John and Heracles Polemarchakis, "We Can't Disagree Forever," Journal of Economic Theory, October 1982, 28, 192-200.

Gibbons, Robert, "Arbitration as a Signaling Game," Unpublished mimeo, April 1986.

Stevens, Carl M., "Is Compulsory Arbitration Compatible with Bargaining?" Industrial Relations, February 1966, 5, 38-52. 